\title{
PREDIKSI JUMLAH LULUSAN MAHASISWA STMIK DUMAI MENGGUNAKAN JARINGAN SYARAF TIRUAN
}

\author{
Masrizal $^{1}$, Atma Hadiansa ${ }^{2}$ \\ ${ }^{1}$ Sekolah Tinggi Manajemen Informatika dan Komputer (STMIK) Dumai \\ ${ }^{2}$ Akademi Manajemen Informatika dan Komputer (AMIK) Dumai \\ ${ }^{1,2} \mathrm{Jln}$. Utama Karya Bukit Batrem Dumai - Riau Kode Pos 28811 \\ masrizalrizal@yahoo.com
}

\begin{abstract}
ABSTRAK
Jumlah lulusan pada dasarnya adalah sebuah target yang ingin dicapai oleh setiap program studi disetiap perguruan tinggi. Dalam prosesnya, mahasiswa yang bisa dikatakan lulus apabila telah menyelesaikan sетиа persyaratan yang telah ditentukan oleh pihakakademik. Namun persentase tingkat kelulusan mahasiswa SI Teknik Informatika STMIK Dumai setiap tahun akademik yang tepat waktu kurang dari target yang telah ditetapkan oleh pihak akademik. Ini disebabkan oleh banyaknya mahasiswa yang tidak mengerti tentang penelitian yang mereka kerjakan sehingga penelitian mereka tidak selesai tepat waktu. Jaringan saraf tiruan (Artificial Neural Network) sebagian besar telah cukup handal dalam pemecahan masalah peramalan yang sering ditemukan dalam proses pengambilan keputusan salah satunya adalah prediksi kelulusan mahasiswa dengan menggunakan metode backpropagation neural network. Dengan diterapkannya metode ini dalam memprediksi jumlah lulusan, dapat diambil kebijakan lebih awal untuk membantu mahasiswa lulus tepat waktu.
\end{abstract}

Kata kunci : Prediksi, Jaringan Syaraf Tiruan, Algoritma Backpropagation, Jumlah Lulusan

\section{PENDAHULUAN}

Tingkat kelulusan mahasiswa pada setiap perguruan tinggi adalah sebuah target yang telah direncanakan dan disusun oleh manajemen program studi agar setiap mahasiswa yang telah menjalani perkuliahan bisa menyelesaikan studinya tepat waktu.

Pada saat ini jumlah lulusan mahasiswa S1 Teknik Informatika STMIK Dumai kalau dipersentasekan berdasarkan tahun akademik atau yang tamat tepat waktu jumlah lulusannya sangat kecil, kondisi tersebut yang membuat menumpuknya jumlah mahasiswa sehingga jumlah dosen tetap dengan rasio mahasiswa menjadi tidak seimbang. Dan pada saat yang bersamaan masih banyak mahasiswa STMIK Dumai mengambil mata kuliah untuk perbaikan nilai yang menyebabkan mahasiswa tidak bisa membagi waktu antara jadwal kuliah dan bimbingan skripsi. Hal ini dipersulit dengan tidak mengertinya mahasiwa tersebut terhadap penelitian yang dibuat.

Berdasarkan fakta diatas salah satu teknik evaluasi tingkat kelulusan secara dini adalah dengan sistem prediksi tingkat kelulusan mahasiswa dimana informasi yang dihasilkan oleh hasil prediksi ini dapat dijadikan sebagai bahan pertimbangan bagi pihak manajemen program studi untuk melakukan langkah persuasif dalam rangka meningkatkan persentasi kelulusan mahasiswa yang memenuhi standar mutu yang ditetapkan kampus.

Prediksi dalam konteks komputasi merupakan salah satu kegiatan matematis. Prediksi ini telah dilakukan bertahun-tahun sebelum penguasaan komputer, yaitu menggunakan alat hitung seperti kalkulator. Prediksi penentuan kelulusan mahasiswa dapat membantu pihak manajemen dalam mengambil keputusan. Bagaimana menganalisa kelulusan mahasiswa dan mendapatkan parameter terbaik dari metode yang digunakan untuk dapat memprediksi kelulusan mahasiswa.

Jaringan Syaraf Tiruan merupakan salah satu sistem pemrosesan informasi yang didesain dengan meniru cara kerja otak manusia dalam menyelesaikan suatu masalah dengan melakukan proses belajar melalui perubahan bobot sinapsisnya. Ada banyak teknik yang dapat digunakan untuk implementasi Jaringan Syaraf Tiruan yaitu Perceptron, Backpropagation dan Fuzzy. Jaringan Syaraf Tiruan dengan menggunakan algoritma backpropagation telah banyak digunakan untuk menyelesaikan beberapa 
IN F ORMA T I K A

Jurnal Informatika, Manajemen dan Komputer, Vol. 9 No. 2, Desember 2017

eISSN : 2580-3042

pISSN : 1979-0694

masalah salah satunya masalah prediksi.

Berdasarkan masalah dan penyebab masalah yang telah dijelaskan diatas, dapat disimpulkan bahwa untuk menanggulanginya diperlukan yaitu dapat melakukan tindakan jika hasil prediksi kelulusan kurang dari standar yang ditetapkan oleh pihak kampus, dapat sebagai pertimbangan bagi pihak manajemen program studi dalam melakukan evaluasi tingkat kelulusan mahasiswa dan membantu pihak jurusan dalam mengevaluasi salah satu matakuliah yang menjadi pendukung tingkat kelulusan sehingga menjadi perbaikan nilai mahasiswa angkatan berikutnya dan dapat meningkatkan kelulusan mahasiswa.

Adapun tujuan dari penelitian ini adalah sebagai berikut :

1. Untuk memprediksi jumlah lulusan mahasiswa STMIK Dumai berdasarkan tahun akademik.

2. Mengimplementasikan jaringan saraf tiruan untuk memprediksi jumlah lulusan pada STMIK Dumai menggunakan metode backpropagation.

\section{a. Pengertian Prediksi}

Prediksi adalah sama dengan ramalan atau perkiraan. Menurut kamus besar bahasa Indonesia, prediksi adalah hasil dari kegiatan mmprediksi atau meramal atau memperkirakan. Prediksi bisa berdasarkan metode ilmiah ataupun subjektif belaka. Sebagai contoh, prediksi cuaca selalu berdasarkan data dan informasi terbaru yang didasarkan pengamatan termasuk oleh satelit. Begitupun prediksi gempa, gunung meletus ataupun bencana secara umum. Namun, prediksi seperti pertandingan sepakbola, olahraga, dan lain-lain umumnya berdasarkan pandangan subjektif dengan sudut pandang sendiri yang memprediksinya. (Diyah Puspitaningrum 2006)

\section{b. Jaringan Saraf Tiruan}

Jaringan syaraf tiruan (JST) adalah sistem pengolah informasi yang meniru sistem syaraf manusia. Sama seperti sistem syaraf manusia yang tersusun oleh neuron, JST juga tersusun oleh perceptron (neuron pada JST) sebagai unit pemrosesan informasi yang merupakan dasar dari operasi JST. ( Fahrudin Julianto et al, 2015)

Jaringan saraf tiruan bisa dibayangkan seperti otak buatan di dalam cerita-certia fiksi ilmiah. Otak buatan ini dapat berpikir seperti manusia, dan juga sepandai manusia dalam menyimpulkan sesuatu dari potongan-

potongan informasi yang diterima. Khayalan manusia tersebut mendorong para peneliti untuk mengujudkannya. Komputer diusahakan agar bisa berpikir sama seperti cara berpikir manusia. Caranya adalah dengan melakukan peniruan terhadap aktivasi-aktivasi yang terjadi di dalam sebuah jaringan saraf biologis (Diyah Puspitaningrum, 2006)

\section{c. Pemodelan Jaringan Syaraf Tiruan (JST)}

Prosedur pemodelan dengan ANN secara umum terdiri dari empat langkah yaitu:

1. Penyiapan data

2. Pemilihan arsitektur

3. Pembelajaran (learning ) dan pengujian (testing)

\section{d. Konsep Dasar Jaringan Syaraf Tiruan}

Setiap pola-pola informasi input dan output yang diberikan kedalam JST diproses dalam neuron. Neuron-neuron tersebut terkumpul di dalam lapisan-lapisan yang disebut neuron layers. Lapisan-lapisan penyusun JaringanSyaraf Tiruan (JST) terhadap suatu permasalahan. tersebut dapat dibagi menjadi 3, yaitu :

1. Lapisan Input, unit-unit di dalam lapisan input disebut unit-unit input. Unit-unit input tersebut menerima pola inputan data dari luar yang menggambarkan suatu permasalahan.

2. Lapisan Tersembunyi, unit-unit di dalam lapisan tersembunyi disebut unit-unit tersembunyi. Di mana outputnya tidak dapat secara langsung diamati.

3. Lapisan Output, unit-unit di dalam lapisan output disebut unit-unit output. Output dari lapisan ini merupakan solusi JaringanSyaraf Tiruan (JST) terhadap suatu permasalahan.

\section{e. Arsitektur Jaringan Saraf Tiruan}

Jaringan Syaraf Tiruan (JST) memiliki beberapa arsitektur jaringan yang sering digunakan dalam berbagai aplikasi. Arsitektur JST tersebut, antara lain, yaitu: (Zekson Arizona Matondang 2013).

1. Jaringan Lapis Tunggal (Single
LayerNetwork) Jaringan lapis tunggal merupakan jaringan yang hanya memiliki satu buah lapisan dengan bobot-bobot yang terhubung. Jaringan ini hanya menerima nilai masukan dan secara langsung mengolahnya untuk menjadi nilai keluaran tanpa melalui lapisan tersembunyi. 
IN F ORMA T I K

Jurnal Informatika, Manajemen dan Komputer, Vol. 9 No. 2, Desember 2017

eISSN : 2580-3042

pISSN : 1979-0694

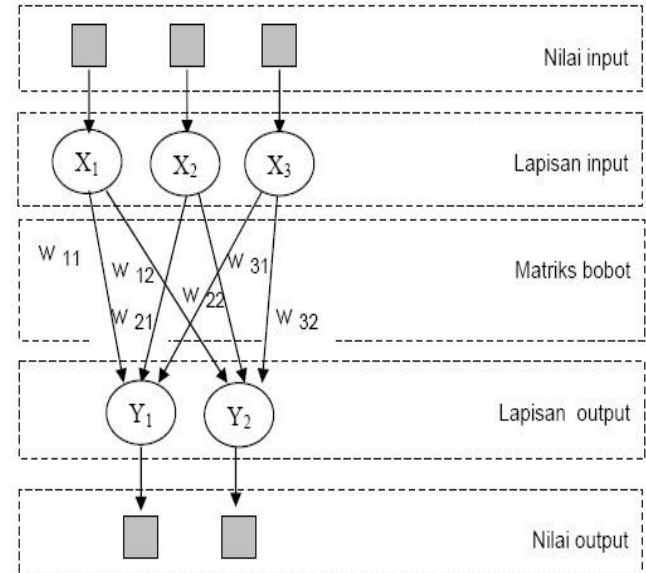

Gambar 1 Jaringan Lapis Tunggal

Sumber: (Diyah Puspitaningrum, 2006)

Pada gambar 1 di atas lapisan input memiliki 3 neuron yaitu $X_{1}, X_{2}$ dan $X_{3}$, sedangkan pada lapisan output memiliki 2 neuron yaitu $Y_{1}$ dan $Y_{2}$. Neuron-neuron pada kedua lapisan saling berhubungan. Seberapa besar antara 2 neuron ditentukan oleh bobot yang besesuaian. Semua unit input akan dihubungkan dengan setiap unit ouput

\section{Jaringan Lapis Jamak (Multi} LayerNetwork)

Jaringan lapis jamak merupakan jaringan yang memiliki satu buah atau lebih lapisan di antara lapisan masukan dan lapisan keluaran. Jaringan lapis jamak ini dapat menyelesaikan permasalahan yang lebih rumit dibandingkan dengan jaringan lapis tunggal walaupun memiliki tingkat kerumitan yang tinggi serta membutuhkan waktu yang lama dalam proses pelatihannya.

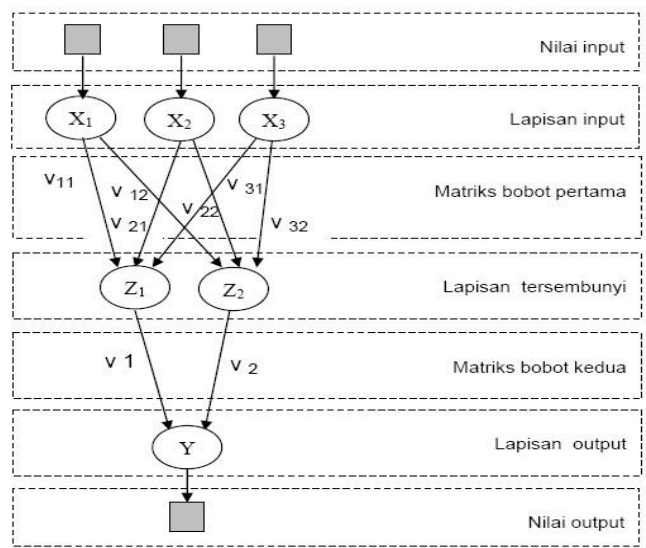

Gambar 2. Jaringan Lapis Jamak

Sumber: (Diyah Puspitaningrum 2006)

\section{f. Metode Backpropagation}

Backpropagation algoritma pembelajaran yang terwarisi dan biasanya digunakan oleh perceptron dengan banyak lapisan untuk mengubah bobot-bobot yang terhubung dengan neuron-neuron yang ada pada lapisan tersembunyinya. Metode ini merupakan metode yang sangat baik dalam menangani masalah pengenalan pola-pola kompleks.

Metode Backpropagation yang digunakan dalam jaringan saraf tiruan dan yang paling sering digunakan dalam berbagai bidang aplikasi, seperti pengenalan pola, peramalan dan optimisasi. Hal ini dimungkinkan karena metode ini menggunakan pembelajaran yang terbimbing. Pola masukan dan target diberikan sebagai sepasang data. Bobot-bobot awal dilatih dengan melalui tahap maju untuk mendapatkan galat keluaran yang selanjutnya galat ini digunakan dengan tahap mundur untuk memperoleh nilai bobot yang sesuai agar dapat memperkecil nilai galat sehinggga target keluaran yang dikehendaki tercapai. (Aditya, 2011).

\section{g. Arsitektur Jaringan Saraf Tiruan Perambatan Balik}

Hubungan antar neuron dalam suatu jaringan dan membentuk lapisan disebut arsitektur jaringan. Arsitektur jaringan saraf perambatan balik terdiri dari beberapa lapisan, yaitu lapisan masukan, lapisan tersembunyi dan lapisan keluaran.

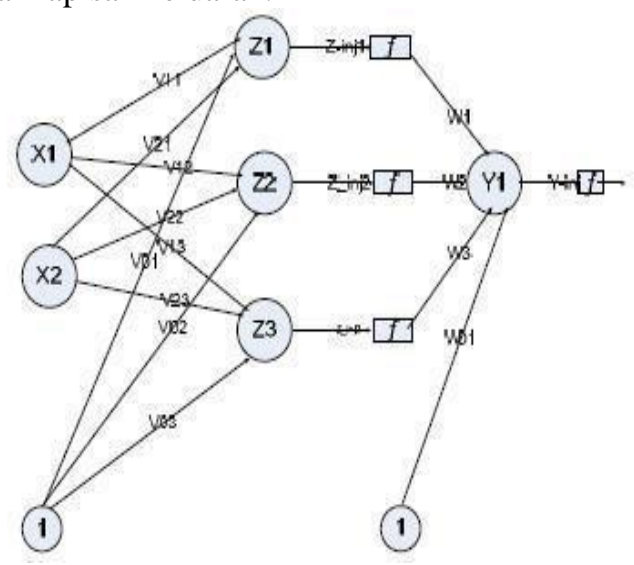

Gambar 3. Arsitektur Jaringan Saraf Perambatan Balik

Sumber: (Diyah Puspitaningrum, 2006)

\section{METODOLOGI PENELITIAN}

Untuk memberikan panduan dalam penyusunan penelitian ini maka perlu adanya susunan kerangka kerja (Frame Work) yang jelas tahapan-tahapannya. Seperti yang terlihat pada gambar 4 . 
IN F ORMA T I K A

Jurnal Informatika, Manajemen dan Komputer, Vol. 9 No. 2, Desember 2017

eISSN : 2580-3042

pISSN : 1979-0694

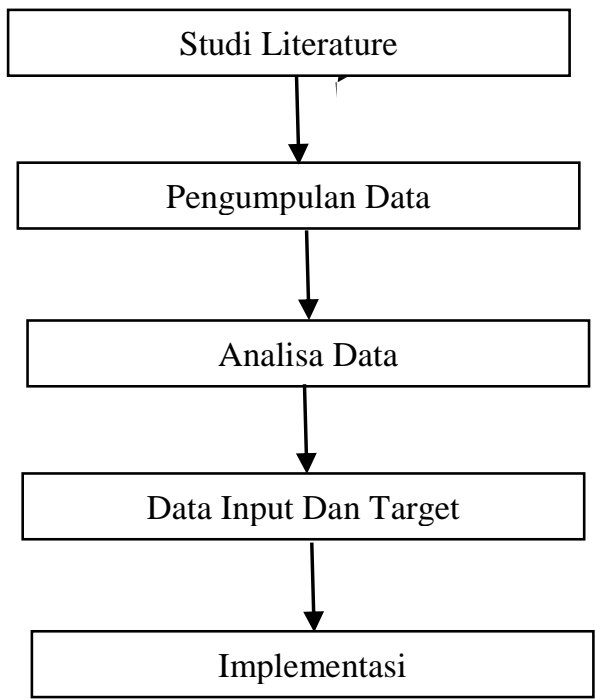

Gambar 4: Kerangka Kerja Penelitian

Secara umum sistematik yang dimaksud terdapat beberapa langkah-langkah yang harus dilakukan dalam pembuatan penelitian ini. Dari kerangka kerja yang di Gambarkan diatas maka dapat diuraikan pembahasan masingmasing kegiatan sebagai berikut ini:

1. Studi Literature

Studi Literature dilakukan dengan tujuan untuk mengetahui metode apa yang akan digunakan untuk menyelesaikan permasalahan yang akan diteliti, serta mendapatkan dasardasar referensi yang kuat bagi peneliti dalam menerapkan suatu metode yang digunakannya.

\section{Pengempulan Data}

Metode pengumpulan data didalam penelitian ini adalah metode observasi. Data yang digunakan dalam penelitian ini menggunakan data akademik dan tahun akademik pada 5 tahun terakhir. Data akademik dan tahun akademik ini dibuat menjadi dua data yaitu training data dan testing data. Training data dan testing data merupakan data mahasiswa yang didata ketika mahasiswa tersebut telah menjadi mahasiswa di Jurusan Teknik Informatika STMIK Dumai

3. Analisa Data

Dalam penelitian ini akan dicari hubungan tingkat kelulusan dengan tahun akademik mahasiswa, yaitu dari nilai IPK semester dua sampai semester delapan sehingga hasil dari proses tersebut dapat dilihat dengan menggunakan IPK nilai yang terbaik yang menghasilkan tingkat keberhasilannya tinggi.

4. Data Input dan Target

Pada tahap ini dilakukan mengolahan data dengan menggunakan jaringan saraf tiruan dengan metode backpropagation, serta menggunakan IPK semester dua sampai semester delapan pada program studi teknik informatika yaitu dengan IPK semester dua sampai delapan untuk data pelatihan dan data uji, untuk mengetahui apakah mahasiswa tersbut bisa lulus tepat waktu dengan menggunakan rumus metode backpropagation

\section{Implementasi}

setelah analisa selesai dilaksanakan maka pada tahap ini dilakukan uji coba terhadap data yang telah dianalisa sehingga hasil dari pada implementasi ini dari pengujian yang telah dilakukan menggunakan matlab 6.1 sebagai alat bantu pengujian dengan menggunakan metode backpropagation. Jika pengujian sudah berjalan dengan lancar, maka sistem dapat diimplementasikan sesuai dengan kebutuhan.

\section{HASIL DAN PEMBAHASAN}

\section{a. Data Input dan Target}

Sebelum proses pengolahan data dilakukan, perlu dilakukan proses penentuan masukan (input) serta target atau hasil yang ingin didapatkan dari proses pengolahan data, sehingga akan memudahkan dalam melakukan pembagian data dan proses pengolahan data untuk mendapatkan hasil sesuai dengan apa yang diharapkan sebelumnya.

\section{b. Data Input}

Data input diperoleh dari IPK mahasiswa program studi teknik informatika STMIK Dumai. Dari hasil IPK tersebut, maka bisa ditentukan kelulusan mahasiswa pada program studi teknik informatika STMIK Dumai berdasarkan tahun akademik tepat waktu atau tidak berikut ini ditampilkan IPK persemester mahasiswa Program Studi Teknik Informatika Tahun Akademik 2012 seperti yang terlihat pada tabel 1 . 
IN F ORMA T I K A

Jurnal Informatika, Manajemen dan Komputer, Vol. 9 No. 2, Desember 2017

eISSN : 2580-3042

pISSN : 1979-0694

Tabel 1. IPK Persemester Mahasiswa Program Studi Teknik Informatika STMIK Dumai TA. 2012.

\begin{tabular}{|l|l|l|c|c|c|c|c|c|c|c|}
\hline \multirow{2}{*}{ No } & \multirow{2}{*}{ NIM } & \multirow{2}{*}{ Nama Mahasiswa } & \multicolumn{7}{|c|}{ IPK Persemester } \\
\cline { 5 - 10 } & & & I & II & III & IV & V & VI & VII & VIII \\
\hline 1. & 2124001 & Ade Syahfitri & 3.05 & 3.19 & 3.16 & 3.20 & 3.19 & 3.27 & 3.25 & 3.24 \\
& & Ningsih & & & & & & & & \\
\hline 2 & 2124003 & Al Ahmad & 2.90 & 2.76 & 2.65 & 2.82 & 3.09 & 3.30 & 3.29 & 3.29 \\
\hline 3 & 2124005 & Anna Annisa & 3.14 & 2.90 & 3.04 & 3.03 & 3.04 & 3.04 & 3.07 & 3.06 \\
\hline 4 & 2124009 & Azrin & 2.36 & 2.65 & 2.73 & 2.78 & 2.86 & 3.00 & 2.95 & 2.97 \\
\hline 5 & 2124013 & $\begin{array}{l}\text { Dwi Guna Putra } \\
\text { Mandala }\end{array}$ & 2.77 & 2.90 & 2.93 & 3.02 & 3.09 & 3.18 & 3.15 & 3.11 \\
\hline 6 & 2124017 & $\begin{array}{l}\text { Indra Okta Viana } \\
\text { Sari }\end{array}$ & 3.09 & 3.19 & 3.04 & 3.04 & 3.09 & 3.11 & 3.07 & 3.04 \\
\hline 7 & 2124019 & $\begin{array}{l}\text { Irsan Maulana } \\
\text { Hadinur }\end{array}$ & 2.91 & 3.16 & 3.17 & 3.25 & 3.22 & 3.26 & 3.25 & 3.24 \\
\hline 8 & 2124028 & Merry Christiany & 2.95 & 3.11 & 3.01 & 3.00 & 2.94 & 3.00 & 3.02 & 3.00 \\
\hline 9 & 2124032 & M. Syaroni & 2.50 & 2.81 & 2.92 & 3.09 & 3.20 & 3.27 & 3.32 & 3.29 \\
\hline 10 & 2124036 & $\begin{array}{l}\text { Nur Chakiki Ratna } \\
\text { Sari }\end{array}$ & 3.00 & 3.20 & 3.20 & 3.23 & 3.26 & 3.36 & 3.33 & 3.33 \\
\hline 11 & 2124037 & Nuraini Putri & 3.45 & 3.48 & 3.50 & 3.47 & 3.36 & 3.44 & 3.45 & 3.42 \\
\hline 12 & 2124040 & Ratna Minarni & 3.18 & 3.34 & 3.23 & 3.17 & 3.20 & 3.27 & 3.24 & 3.20 \\
\hline 13 & 2124043 & Sandi Fadilah & 3.41 & 3.37 & 3.35 & 3.35 & 3.44 & 3.44 & 3.42 & 3.45 \\
\hline 14 & 2124046 & Syafril Legianto & 3.00 & 3.20 & 3.20 & 3.23 & 3.26 & 3.36 & 3.33 & 3.33 \\
\hline
\end{tabular}

Tabel 1 di atas merupakan data nilai IPK Persemeter yang belum dinormalisasikan. Untuk itu tabel 1 di atas akan di rubah kedalam bentuk normalisasi dengan rumus :

$x^{\prime}=\frac{0.8(\mathrm{x}-\mathrm{a})}{\mathrm{b}-\mathrm{a}}+0.1$

di mana :

$\mathrm{x}=$ Nilai Input

$\mathrm{a}=$ Nilai minimum

$\mathrm{b}=$ Nilai maksimum.

Tabel 2. Hasil Normalisasi IPK Persemester Mahasiswa Program Studi Teknik Informatika STMIK Dumai TA. 2012

\begin{tabular}{|c|c|c|c|c|c|c|c|c|c|c|}
\hline \multirow{2}{*}{ No } & \multirow{2}{*}{ NIM } & \multirow{2}{*}{ Nama Mahasiswa } & \multicolumn{8}{|c|}{ IPK Persemester } \\
\hline & & & $\mathrm{I}$ & III & IIII & IV & $\mathrm{v}$ & VI & VIII & VIII \\
\hline 1. & 2124001 & Ade Syahfitri & 0.60 & 0.62 & 0.58 & 0.58 & 0.55 & 0.59 & 0.58 & 0.55 \\
\hline 2 & 2124003 & Al Ahmad & 0.49 & 0.20 & 0.10 & 0.14 & 0.41 & 0.65 & \begin{tabular}{|l|l|}
0.64 \\
\end{tabular} & 0.63 \\
\hline 3 & 2124005 & Anna Anni & 0.67 & 0.34 & 0.46 & 0.39 & 0.34 & 0.17 & 0.29 & 0.25 \\
\hline 4 & 2124009 & Azrin & 0.10 & 0.10 & 0.17 & 0.10 & 0.10 & 0.10 & 0.10 & 0.10 \\
\hline 5 & 2124013 & Dwi Guna Putra & 0.40 & 0.37 & 0.36 & 0.37 & 0.41 & 0.43 & 0.42 & 0.33 \\
\hline 6 & 2124017 & $\begin{array}{l}\text { Indra Okta Viana } \\
\text { Sari }\end{array}$ & 0.63 & 0.62 & 0.46 & 0.40 & 0.41 & 0.30 & 0.29 & 0.22 \\
\hline 7 & 2124019 & Irsan Maulana & 0.50 & 0.59 & 0.58 & 0.64 & 0.59 & 0.57 & 0.58 & 0.55 \\
\hline & & Hadinur & & & & & & & & \\
\hline 8 & 2124028 & Merry Christiany & 0.53 & 0.54 & 0.43 & 0.35 & 0.21 & 0.10 & 0.21 & 0.15 \\
\hline 9 & 2124032 & M. Syaroni & 0.20 & 0.25 & 0.35 & 0.45 & 0.56 & 0.59 & 0.69 & 0.63 \\
\hline 10 & 2124036 & $\begin{array}{l}\text { Nur Chakiki Ratna } \\
\text { Sari }\end{array}$ & 0.57 & 0.63 & 0.61 & 0.62 & 0.65 & 0.75 & 0.71 & 0.70 \\
\hline 11 & 2124037 & Nuraini Putri & 0.90 & 0.90 & 0.90 & 0.90 & 0.79 & 0.90 & 0.90 & 0.85 \\
\hline 12 & 2124040 & Ratna Minarni & 0.70 & 0.76 & 0.64 & 0.55 & 0.56 & 0.59 & 0.56 & 0.48 \\
\hline 13 & 2124043 & Sandi Fadilah & 0.87 & 0.79 & 0.75 & 0.76 & 0.90 & 0.90 & 0.85 & 0.90 \\
\hline 14 & 2124046 & Syafril Legianto & 0.57 & 0.63 & 0.61 & 0.62 & 0.65 & 0.75 & 0.71 & 0.70 \\
\hline
\end{tabular}

Tabel 2 di atas merupakan hasil dari normalisasi dari IPK mahasiswa Program

Studi teknik informatika Tahun Akademik 2012

\section{c. Data Target}

Adapun data target adalah 1 menunjukkan IPK 2,75 - 4,00, sedangkan 0 menunjukkan IPK 0,00-2,74. Data target dapat dilihat pada tabel 3 .

Tabel 3. Data Target

\begin{tabular}{|c|c|c|}
\hline No & Keterangan & Bobot \\
\hline 1 & $2,75-4,00$ & 1 \\
\hline 2 & $0,00-2,74$ & 0 \\
\hline
\end{tabular}

\section{d. Pengolahan Data}

Pengolahan data yang akan dilakukan adalah memberikan nilai target atau output kepada IPK mahasiswa prodi teknik informatika berdasarkan IPK terakhir mahasiswa tersebut. Data IPK mahasiswa STMIK Dumai berdasarkan target atau output yang dipilih terdapat pada Tabel 4 berikut:

Tabel 4. Data Nilai IPK Sesuai Target STMIK Dumai

\begin{tabular}{|l|c|l|c|c|c|c|c|c|c|c|c|}
\hline \multirow{2}{*}{ No } & \multirow{2}{*}{ NIM } & \multicolumn{1}{|c|}{$\begin{array}{c}\text { Nama } \\
\text { Mahasiswa }\end{array}$} & \multicolumn{7}{|c|}{ IPK Persemester } & \multirow{2}{*}{ Target } \\
\hline 1. & 2124001 & $\begin{array}{l}\text { Ade Syahfitri } \\
\text { Ningsih }\end{array}$ & 0.60 & 0.62 & 0.58 & 0.58 & 0.55 & 0.59 & 0.58 & 0.55 & 1 \\
\hline 2 & 2124003 & Al Ahmad & 0.49 & 0.20 & 0.10 & 0.14 & 0.41 & 0.65 & 0.64 & 0.63 & 1 \\
\hline 3 & 2124005 & Anna Annisa & 0.67 & 0.34 & 0.46 & 0.39 & 0.34 & 0.17 & 0.29 & 0.25 & 1 \\
\hline 4 & 2124009 & Azrin & 0.10 & 0.10 & 0.17 & 0.10 & 0.10 & 0.10 & 0.10 & 0.10 & 1 \\
\hline 5 & 2124013 & $\begin{array}{l}\text { Dwi Guna } \\
\text { Putra } \\
\text { Mandala }\end{array}$ & 0.40 & 0.37 & 0.36 & 0.37 & 0.41 & 0.43 & 0.42 & 0.33 & 1 \\
\hline 6 & 2124017 & $\begin{array}{l}\text { Indra Okta } \\
\text { Viana Sari }\end{array}$ & 0.63 & 0.62 & 0.46 & 0.40 & 0.41 & 0.30 & 0.29 & 0.22 & 1 \\
\hline 7 & 2124019 & $\begin{array}{l}\text { Irsan } \\
\text { Maulana } \\
\text { Hadinur }\end{array}$ & 0.50 & 0.59 & 0.58 & 0.64 & 0.59 & 0.57 & 0.58 & 0.55 & 1 \\
\hline 8 & 2124028 & $\begin{array}{l}\text { Merry } \\
\text { Christiany }\end{array}$ & 0.53 & 0.54 & 0.43 & 0.35 & 0.21 & 0.10 & 0.21 & 0.15 & 1 \\
\hline 9 & 2124032 & M. Syaroni & 0.20 & 0.25 & 0.35 & 0.45 & 0.56 & 0.59 & 0.69 & 0.63 & 1 \\
\hline 10 & 2124036 & $\begin{array}{l}\text { Nur Chakiki } \\
\text { Ratna Sari }\end{array}$ & 0.57 & 0.63 & 0.61 & 0.62 & 0.65 & 0.75 & 0.71 & 0.70 & 1 \\
\hline 11 & 2124037 & Nuraini Putri & 0.90 & 0.90 & 0.90 & 0.90 & 0.79 & 0.90 & 0.90 & 0.85 & 1 \\
\hline 12 & 2124040 & $\begin{array}{l}\text { Ratna } \\
\text { Minarni }\end{array}$ & 0.70 & 0.76 & 0.64 & 0.55 & 0.56 & 0.59 & 0.56 & 0.48 & 1 \\
\hline 13 & 2124043 & $\begin{array}{l}\text { Sandi } \\
\text { Fadilah }\end{array}$ & 0.87 & 0.79 & 0.75 & 0.76 & 0.90 & 0.90 & 0.85 & 0.90 & 1 \\
\hline 14 & 2124046 & $\begin{array}{l}\text { Syafril } \\
\text { Legianto }\end{array}$ & 0.57 & 0.63 & 0.61 & 0.62 & 0.65 & 0.75 & 0.71 & 0.70 & 1 \\
\hline
\end{tabular}

Setelah dilakukan pengujian dengan menggunakan matlab pada data mahasiswa program studi teknik informatika tahun akademik 2012 berdasarkan hasil pengujian mahasiswa tersebut bisa menyelesaikan masa studi nya tepat pada waktu yang telah ditentukan oleh pihak akademis dalam hal ini program studi seperti yang terlihat pada gambar tabel 4 di atas. 
INFORMA TIK A

Jurnal Informatika, Manajemen dan Komputer, Vol. 9 No. 2, Desember 2017

eISSN : 2580-3042

pISSN : 1979-0694

\section{e. Hasil Pengujian Dengan Matlab}

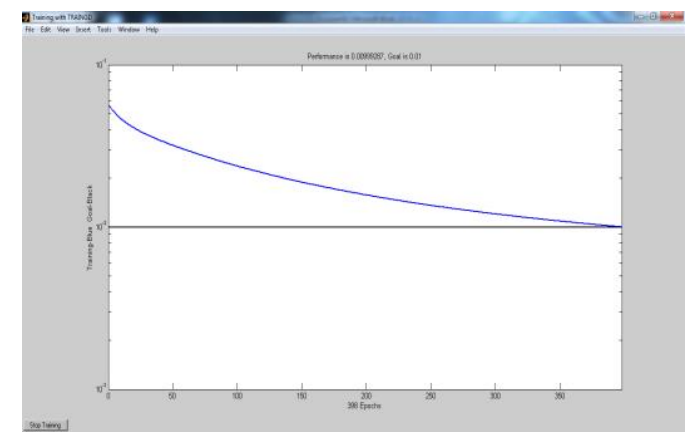

Gambar 4. Pelatihan IPK Mahasiswa dengan Pola 8-2-1 Mencapai Goal

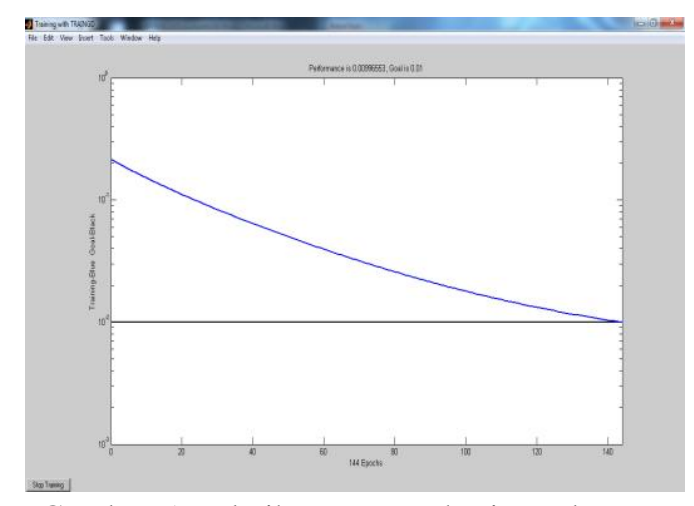

Gambar 5. Pelatihan IPK Mahasiswa dengan Pola 8-3-1 Mencapai Goal

Gambar 4 dan 5 di atas menujukkan pengujian menggunakan matlab untuk mentukan goal terhadap data yang diujikan, berdasarkan hasil yang telah dicapai semakin banyak hidden layar pada suatu pola dengan menggunakan metode Backpropagation maka data tersebut akan cepat dikenali atau mencapai goalnya.

\section{KESIMPULAN}

Kesimpulan yang diperoleh dari penelitian ini adalah:

1. Dari hasil yang didapatkan bahwa dengan menggunakan software matlab semua data yang diujikan atau dilatih dapat diikenali dengan baik

2. Dengan menggunakan penerapan algoritma Backpropagation Neural Network dapat digunakan untuk memprediksi hasil prestasi mahasiswa terutama pada STMIK Dumai

\section{REFERENSI}

Aditya Wibowo (2011). "Jurnal Pengenalan Huruf Jawa Tulisan Tangan MenggunakanJaringan Saraf Tiruan
Perambatan Balik Dengan Fuzzy Feature Extraction

Diyah Puspitaningrum (2006) Pengantar Jaringan Saraf Tiruan”, Penerbit Andi, Yogyakarta.

Fahrudin Julianto etc all. (2015) "Jurnal Analisis dan Implementasi Algoritma DifferentialEvolution Pada Jaringan Syaraf Tiruan Studi Kasus Prediksi Masa Studi Mahasiswa"

Relita Buaton etc all. (2012) Jurnal "Prediksi mahasiswa yang tidak menyelesaikan pendidikan tidak tepat waktu dengan menggunakan data mining metode backpropagation (studi kasus STMIK Kaputama Binjai)"

Zekson Arizona Matondang (2013). “ Jurnal Jaringan Syaraf Tiruan Dengan AlgoritmaBackpropagation Untuk Penentuan Kelulusan Sidang Skripsi” 